\title{
Algunas cuestiones técnico jurídicas sobre los protocolos contra el acoso sexual y por razón de sexo en las Universidades Públicas
}

\author{
María Almodóvar Iñesta \\ Profesora Titular de Derecho Administrativo \\ Universidad de Alicante
}

\begin{abstract}
SUMARIO: I.GUESTIONES INTRODUGTORIAS RESPEGTO A LOS PROTOCOLOS FRENTE AL ACOSO SEXUAL Y POR RAZÓN DE SEXO EN LAS UNIVERSIDADES PÚBLICAS. 1. Justificación de este trabajo. 2. Guestiones Generales: A. Marco Jurídico. B. Justificación de Protocolos específicos de prevención y actuación frente al acoso sexual y por razón de sexo en las Universidades Públicas. C. Contenidos. D. Finalidad. E. Garantías comunes a todos los procedimientos. II.CUESTIONES TÉGNICOJURÍDICAS QUE PLANTEAN LOS PROTOGOLOS DE PREVENGIÓN Y ACTUACIÓN CONTRA EL ACOSO SEXUAL Y EL ACOSO POR RAZÓN DE SEXO. 1. Definición de acoso sexual y acoso por razón de sexo. 2.Ámbito subjetivo de los protocolos. 3. Modalidades de procedimientos de actuación previstos en los Protocolos. 4. Aproximación de los procedimientos de resolución formal a la información reservada de un expediente disciplinario. 5. La adopción de medidas provisionales. 6. Sobre la inversión de la carga de la prueba. III. CONCLUSIONES
\end{abstract}

RESUMEN: En cumplimiento del mandato contenido en el artículo 62.1 de la Ley Orgánica 3/2007 para la igualdad efectiva de mujeres y hombres, las Universidades Públicas han articulado en sus respectivos ámbitos, protocolos de actuación frente al acoso sexual o por razón de sexo, que se configuran como primer mecanismo de actuación frente a este tipo de actos. Estos instrumentos plantean una serie de cuestiones técnico-jurídicas que han sido objeto de estudio en este trabajo.

PALABRAS CLAVE: protocolos, universidades, acoso sexual, acoso por razón de sexo, inversión de la carga de la prueba.

ABSTRACT: In compliance with the mandate contained in article 62.1 of the Organic Law 3/2007 for the effective equality of women and men, the Public Universities have articulated in their respective areas, protocols of action against sexual 
harassment or by reason of sex that are configured as the first mechanism of action against this type of acts. These instruments raise a series of technical-legal issues that have been the object of study in this work.

KEY WORDS: protocols, universities, sexual harassment, sex harassment, reversal of the burden of proof.

\section{I.CUESTIONES INTRODUGTORIAS RESPECTO A LOS PROTO- GOLOS FRENTE AL ACOSO SEXUAL Y POR RAZÓN DE SEXO EN LAS UNIVERSIDADES PÚBLICAS}

\section{Justificación de este trabajo}

La Ley Orgánica 3/2007, para la igualdad efectiva de mujeres y hombres (LOI), en su Título V "El principio de igualdad en el empleo público" y concretamente en el artículo 62.1 establece la obligación de las Administraciones Públicas de negociar con la representación legal de las trabajadoras y trabajadores, un protocolo de actuación frente al acoso sexual y al acoso por razón de sexo.

En cumplimiento de este mandato, las Universidades Públicas han articulado en sus respectivos ámbitos protocolos de actuación para estos supuestos, con un doble objetivo, por una parte prevenir, visibilizar y sensibilizar a la comunidad universitaria sobre estas cuestiones y por otra, establecer de forma clara las pautas de actuación específicas para abordar las situaciones que regulan.

En este contexto, su estudio suscita una serie de cuestiones técnico-jurídicas diversas que se han intentado plasmar en este trabajo y que se refieren fundamentalmente a los siguientes aspectos:

1. La definición de acoso sexual y acoso por razón de sexo. Aunque la LOI ofrece una definición de estas conductas que ha sido adoptada por los protocolos, resulta necesario utilizar los elementos y matices que establecen los tribunales para determinar cuando una conducta es constitutiva de acoso sexual y cuando rebasa el ámbito administrativo para convertirse en delito.

2. La diversidad de los protocolos en cuanto a su ámbito subjetivo, puesto que no todos incluyen a los mismos colectivos en su ámbito de aplicación y en consecuencia no todos ellos gozarán de la misma eficacia y de un elemento distintivo respecto a los procedimientos de prevención de riesgos laborales.

3. Las modalidades de procedimientos de actuación previstos y su idoneidad para gestionar de forma ordenada este tipo de asuntos de los que, en su caso, podría 
derivarse, si existen motivos fundados para ello, el correspondiente expediente disciplinario.

4. La aproximación de los procedimientos de resolución formal previstos a la información reservada del artículo 28 del Reglamento de Régimen Disciplinario de los Funcionarios de la Administración del Estado, en cuanto a su configuración como una vía previa de la que puede derivarse la incoación de un expediente disciplinario.

5. La adopción de medidas provisionales por el órgano competente para resolver, conforme a la nueva regulación del artículo 56 de la Ley 39/20151.

6. Sobre la efectiva aplicación de la inversión de la carga de la prueba del artículo 13 de la LOI y la legalidad de su aplicación a los procedimientos previstos en los mismos, así como a los posibles expedientes disciplinarios posteriores.

\section{Cuestiones generales}

\section{A. Marco Jurídico}

Entre las medidas para la promoción de la igualdad efectiva entre hombres y mujeres y para la protección frente al acoso sexual y por razón de sexo, el artículo 62.1 de la LOI prevé que "las Administraciones públicas negociarán con la representación legal de trabajadoras y trabajadores, un protocolo de actuación que comprenderá, al menos, los siguientes principios:

a) El compromiso de la Administración General del Estado y de los organismos públicos vinculados o dependientes de ella de prevenir y no tolerar el acoso sexual y el acoso por razón de sexo.

b) La instrucción a todo el personal de su deber de respetar la dignidad de las personas y su derecho a la intimidad, así como la igualdad de trato entre mujeres y hombres.

c) El tratamiento reservado de las denuncias de hechos que pudieran ser constitutivos de acoso sexual o de acoso por razón de sexo, sin perjuicio de lo establecido en la normativa de régimen disciplinario.

d) La identificación de las personas responsables de atender a quienes formulen una queja o denuncia ${ }^{2}$."

\footnotetext{
1 Ley 39/2015, de 1 de octubre, del Procedimiento Administrativo Común de las Administraciones Públicas

2 Como señala GINÈS I FABRELLAS, estos cuatro principios mínimos pueden resumirse en dos medidas preventivas y dos de procedimiento. Como medidas preventivas el compromiso de no tolerancia y
} 
De esta forma y sin perjuicio de lo establecido en la normativa de régimen disciplinario, las Universidades han articulado en base a estos contenidos mínimos, protocolos ${ }^{3}$ de prevención y actuación para aquellos casos en que se produzca acoso sexual o por razón de sexo en sus ámbitos territoriales, e incluso algunos de ellas han incluido en su ámbito de aplicación conductas no contempladas en el mandato del artículo 62, como el acoso por orientación sexual ${ }^{4}$.

Resulta oportuno conectar estas previsiones con el Estatuto Básico del Empleado Público, de hecho el Proyecto de Ley de 2007 fue objeto de una enmienda que tiene como propósito incorporar los distintos supuestos de acoso previstos en el proyecto de Ley Orgánica para la igualdad efectiva de mujeres y hombres, recogiendo el acoso sexual y por razón de sexo 5 .

Como resultado, el Texto Refundido del Estatuto Básico del Empleado Públi$\operatorname{co}^{6}$ (TREBEP) en su Exposición de Motivos afirma que "por primera vez se establece

la instrucción de los empleados, como medidas de procedimiento el tratamiento reservado de las denuncias e identificación de los responsables de atender a dichas denuncias (2006): pp.218 - 219

3 Tienen Protocolos de actuación frente al acoso sexual o por razón de sexo: Universidad de Alicante, Universidad de Valencia, Universidad del País Vasco, Universitat de Lleida, Universidad de la Laguna, Universidad de Valladolid, Universitat Politècnica de València, Universidad de Murcia, Universitat Rovira i Virgili, Universidad de Zaragoza, Universitat Ramón Llull, Universitat Pompeu Fabra, Universitat Politècnica de Catalunya, Universitat Oberta de Catalunya, Universidad Nacional de Educación a Distancia, Universitat Jaume I, Universitat de Barcelona, Universitat Autònoma de Barcelona, Universidad de Sevilla, Universidad de Jaén, Universidad de Córdoba, Universidad Carlos III de Madrid, Universidad de Cádiz y Universidad de Granada, Universidad Pablo de Olavide de Sevilla, Universidad Autónoma de Madrid, Universidad Politécnica de Madrid, Universidad de Santiago de Compostela y Universidad de Vigo, entre otras.

4 Véase el Protocolo de prevención y actuación frente al acoso sexual, por razón de sexo y por orientación sexual de la Universidad de Alicante, BOUA de 3 de julio de 2015

En el preámbulo se justifica la inclusión del acoso por razón de orientación sexual en que "constituye una causa proscrita de discriminación (art.21 de la Carta de Derechos Fundamentales de la Unión Europea)......constituyen actos de coacción que ignoran la voluntad de quien las padece, atentan contra su dignidad, niegan el respeto a su integridad física y psíquica, y convierten el sexo o la orientación sexual en objeto de hostilidad"

Protocolo de la Universidad de Lleida, que en su artículo 1 dispone "El reglamento tiene como objetivo hacer efectiva la igualdad (en dignidad) eliminando las discriminaciones y las situaciones de acoso sexual, acoso por razón de sexo y de orientación sexual y la violencia en el ámbito de pareja que se produce en la UL"

También en el Plan de Prevención de Riesgos Laborales de la Universitat Pompeu Fabra, se incluye el acoso por razón de orientación u opción sexual.

5 Esta enmienda se justifica como mejora técnica que "trata de contemplar los distintos supuestos de acoso y se tiene en cuenta el tenor literal del Proyecto de Ley Orgánica para la igualdad efectiva de mujeres y hombres, recogiendo el acoso sexual y por razón de sexo". Enmienda núm.277 del Grupo Parlamentario Socialista, BOCG-Senado-núm.85(d), de 21 de febrero de 2007, pág. 149

${ }_{6}$ Real Decreto Legislativo 5/2015, de 30 de octubre, por el que se aprueba el testo refundido de la Ley del Estatuto Básico del Empleado Público. 
en nuestra legislación una regulación general de los deberes básicos de los empleados públicos, fundada en principios éticos y reglas de comportamiento, que constituye un auténtico código de conducta”. Así en su Título III, Capítulo I, al enumerar los derechos de los empleados públicos, reconoce el derecho "al respeto de su intimidad, orientación sexual, propia imagen y dignidad en el trabajo, especialmente frente al acoso sexual y por razón de sexo, moral y laboral". Más adelante, en el Capítulo VI titulado Deberes de los empleados públicos. Código de conducta, prevé que "los principios y reglas establecidos en este Capítulo informarán la interpretación y aplicación del régimen disciplinario de los empleados públicos" " y a continuación como principio ético establece que "su conducta se basará en el respeto de los derechos fundamentales y libertades públicas, evitando toda actuación que pueda producir discriminación alguna por razón de nacimiento, origen racial o étnico, género, sexo, orientación sexual, religión o convicciones, opinión, discapacidad, edad o cualquier otra condición o circunstancia personal o social”. En coherencia con todo ello, el artículo 95.2.b) del TREBEP, tipifica como falta muy grave "toda actuación que suponga discriminación por razón de origen racial o étnico, religión o convicciones, discapacidad, edad u orientación sexual, lengua, opinión, lugar de nacimiento o vecindad, sexo o cualquier otra condición o circunstancia personal o social, así como el acoso por razón de origen racial o étnico, religión o convicciones, discapacidad, edad u orientación sexual y el acoso moral, sexual y por razón de sexo", aunque no ofrece una definición de estas conductas.

En consecuencia y sin perjuicio de las previsiones respecto a las pautas de actuación específicas dispuestas en los protocolos, el acoso sexual y el acoso por razón de sexo son conductas tipificadas como infracción muy grave por el TREBEP y en su caso como delito cuando se cumplan los requisitos previstos en el artículo 184 del Código Penal.

B. Justificación de Protocolos específicos de prevención y actuación frente al acoso sexual y por razón de sexo en las Universidades Públicas

Los protocolos de actuación frente al acoso sexual en las Universidades, se configuran como un instrumento, que persigue un doble objetivo en el ámbito de las relaciones laborales y académicas; por una parte evitar y tratar de prevenir cualquier situación de acoso, y por otra articular un procedimiento que permita actuar, con todas las garantías, siempre que se produzca una situación de acoso sexual, o en su caso, acoso por razón de sexo.

Una de las cuestiones que nos planteamos, es la necesidad de adoptar protocolos específicos para la prevención del acoso sexual o si sería suficiente el tratamiento

Artículo 52, párrafo $2^{\circ}$ 
de esta cuestión en otro tipo de normas como las relativas a la prevención de violencia en el trabajo o riesgos psicosociales. Al respecto, la doctrina mayoritaria entiende que incluir el acoso sexual dentro de un marco más genérico, conllevaría a su invisibilización y dificultaría la concienciación en torno a esta problemática, lo que no impide que se complementen con medidas preventivas contra los riesgos psicosociales que incluyan el acoso sexual para conseguir una política de prevención eficaz ${ }^{8}$. En la actualidad, la mayoría de Universidades ha seguido esta vía y han aprobado protocolos específicos en materia de acoso sexual, de esta forma se visibiliza un problema al que la Universidad no es ajena, ofreciendo una mayor seguridad jurídica, en cuanto que se articula el procedimiento que se seguirá en estos casos, garantizando como mínimo los principios previstos en el artículo 62.1 de la LOI.

Otra cuestión importante es el instrumento jurídico adecuado para aprobarlos y dotarles de carácter normativo. Se trata de normas reglamentarias aprobadas por el órgano de gobierno de cada Universidad, que en la mayor parte de los casos es el Consejo de Gobierno. De este modo quedan vinculados al mismo todos los colectivos incluidos en su ámbito de aplicación (funcionarios públicos, personal laboral, estudiantes) en el marco de su relación especial de sujeción con la Universidad. En cuanto al lugar que ocupan en el ordenamiento jurídico, resaltar que se trata de normas reglamentarias que establecen pautas de actuación específicas frente a conductas que lesionan derechos fundamentales y que se articulan siguiendo el mandato del artículo 62.1 de la LOI. En consecuencia, tienen un papel complementario respecto a la normativa relativa a estas conductas, desarrollando y adaptando la misma a la realidad concreta de cada Universidad

\section{Contenidos}

Aclarada la procedencia de instrumentos específicos en esta materia, cabe plantearse cual debe ser el contenido de los mismos, al respecto señalan BODELÓN GONZÁLEZ y GALA DURÁN ${ }^{9}$ que aunque lo deseable hubiese sido que la LOI identificara de forma clara los mecanismos de prevención de los que se deben dotar las administraciones, lo cierto es que no lo hace, por lo que la mayoría de protocolos han incluido como medidas de prevención las indicadas por el Código de Conducta de la Comisión Europea para combatir el acoso sexual ${ }^{10}$ : a) formulación de una declaración de principios que concrete los derechos de los trabajadores y definición

8 PUMAR BELTRÁN (2015): p.278

9 BODELÓN GONZÁLEZ y GALA DURÁN (2014): p.101

10 Recomendación 1992/131/CEE, de 27 de noviembre, de la Comisión de las Comunidades Europeas, sobre la protección y dignidad de la mujer y el hombre en el trabajo. Anexo sobre protección de la dignidad de la mujer y del hombre en el trabajo. 
de conceptos, b) comunicación de la declaración de principios, c) políticas para la asunción de responsabilidades y d) formación ${ }^{11}$.

A estas medidas se suman otras como la evaluación del entorno laboral ${ }^{12}$, con la inclusión de encuestas que permitan detectar estas situaciones de acoso y el seguimiento de la aplicación de los protocolos, creando a este efecto registros estadísticos de los casos tramitados sin revelar los datos de las personas afectadas. Y en todos ellos, se articulan los procedimientos de actuación en supuestos que pudieran ser constitutivos de acoso sexual incluyendo los contenidos mínimos procedimentales previstos por el artículo 62 de la LOI, garantizando el tratamiento reservado de las denuncias y facilitando la identificación de las personas responsables de atender a quienes formulen las mismas.

\section{Finalidad}

Además de establecer medidas preventivas, los protocolos universitarios de actuación frente al acoso sexual o por razón de sexo se configuran como primer mecanismo de actuación frente a este tipo de actos, proporcionando una vía preestablecida de solución a la situación planteada.

Muchos de ellos han sido influenciados por la formulación del protocolo de la Administración General del Estado ${ }^{13}$ que insiste en que la actuación debe ser lo más temprana posible para que produzcan el menor efecto sobre quienes las sufren y se sancione a quienes la producen, disponiendo una serie de aspectos comunes como una declaración de compromisos y la configuración de las unidades responsables para la programación de la formación e información.

En este contexto, cada Universidad ha diseñado un procedimiento de actuación propio con perfiles diversos en cuanto al ámbito subjetivo, desarrollo del procedimiento y estructuras competentes. En la mayoría de casos, se configura la mediación como primera vía de solución y en caso de no ser viable dará lugar a un procedimiento formal ante un órgano instructor que decidirá sobre la existencia de acoso, que propondrá a los órganos ejecutivos las medidas procedentes, inclusive, en su caso, la incoación de un expediente disciplinario por falta muy grave.

\footnotetext{
11 Vid. GINÈS I FABRELLAS (2006): p.216

12 Protocolo de la Universidad de Alicante, Protocolo de la Universidad de La Laguna, Universidad de Valladolid, Protocolo de la UNED.

13 Resolución de 28 de julio de 2011, de la Secretaria de Estado para la Función Pública, por la que se aprueba y publica el Acuerdo de 27 de julio de 2011 de la Mesa General de Negociación de la Administración General del Estado sobre el Protocolo de actuación frente al acoso sexual y al acoso por razón de sexo en el ámbito de la Administración General del Estado y de los Organismos Públicos vinculados a ella. BOE núm.189, de 8 de agosto de 2011
} 
E. Garantías comunes a todos los procedimientos

Los protocolos identifican una serie de principios que con diferentes finalidades deben fundamentar los procedimientos de actuación, de éstos los más reiterados son:

Confidencialidad que alcanza a la identidad de todas y cada una de las personas que intervengan en el procedimiento y de la información que se derive del mismo, tanto en el proceso de investigación como después de finalizado el mismo. Para ello, se incluyen diversas medidas como la asignación de códigos numéricos de identificación de las partes, la solicitud de registro de denuncia acompañada de sobre cerrado con el lema "confidencial" , la custodia de toda la documentación por una única unidad, indicación expresa a los implicados del deber de custodia o consulta de actas in situ.

En la práctica, no resulta fácil garantizar esa confidencialidad, de hecho y a pesar de la previsión de asignar códigos numéricos, en el supuesto de seguir el procedimiento de resolución, la comisión encargada tendrá que conocer la identidad de las partes y practicar cuantas actuaciones estime oportunas, entre ellas, llamar a testigos que necesariamente tienen que conocer de la identidad de las partes y que aun siendo informados de este deber puede que no lo cumplan. No se incluyen en los protocolos ni la firma de una cláusula de confidencialidad para cada uno de los sujetos que intervengan en el procedimiento, ni la correspondiente sanción disciplinaria en caso de incumplimiento de la misma con cobertura legal en el artículo 95.2.a) del EBEP ${ }^{14}$.

Desde esta perspectiva, sería conveniente que todos los Protocolos incluyesen medidas concretas dirigidas al cumplimiento de esta garantía, que conforme a la estructura del procedimiento podrían ser:

1. Presentación de la denuncia, entendiendo que ya en este momento se debe preservar la confidencialidad. Para ello, debemos distinguir si es escrita o verbal. En el primer caso, resultan convenientes previsiones que permitan su presentación, bajo la mención expresa de "confidencial" y en sobre cerrado ${ }^{15}$. En el supuesto de ser verbal, sería oportuna la firma de una cláusula de confidencialidad por el denunciante que preserve la dignidad e intimidad del denunciado.

$14 \quad$ El artículo 95.2.e) EBEP, tipifica como infracción muy grave "La publicación o utilización indebida de la documentación o información a que tengan o hayan tenido acceso por razón de su cargo o función"

Este modelo es seguido por los Protocolos de pocas Universidades, entre ellas la Universidad de Alicante. 
2. En el momento de recepción de la denuncia por el órgano competente

En este momento, el órgano competente para la recepción debería asignar códigos numéricos identificativos que permitan preservar la identidad, tanto al denunciante como de la persona que presuntamente ha llevado a cabo el acoso ${ }^{16}$, de esta forma toda la documentación contenida en el expediente se generará con los códigos identificativos, omitiéndose, en cualquier caso, la identidad nominal de las partes implicadas en el procedimiento. Evidentemente, los miembros del órgano colegiado que tramiten el procedimiento y las personas que participen en el mismo conocerán de la identidad de estos sujetos, por lo que serán informados de su deber de confidencialidad y de las consecuencias de su incumplimiento conforme al artículo 95.2.e) del EBEP.

A partir de la recepción de la denuncia comienza a generarse documentación que deberá ser custodiada y archivada por un órgano determinado previamente; de modo que cualquier consulta de la misma, se realizará in situ, garantizando que ningún documento salga de las dependencias del órgano designado ${ }^{17}$.

\section{Durante la tramitación del procedimiento}

En los protocolos se genera documentación, que en todo caso identificará a las partes a través de códigos numéricos y que será remitida al órgano competente para custodiar la documentación al final de cada sesión, a través de sobre cerrado que contendrá el número del expediente y la mención de confidencial.

Además, sería conveniente que la intervención de cualquier persona en el procedimiento se realice bajo la firma de una cláusula de confidencialidad que recordase la vigencia de esta obligación durante y después de la finalización del mismo.

4. Finalizado el procedimiento

Se mantiene la obligación de confidencialidad respecto a la identidad de todas las personas que han intervenido y de la información derivada del mismo ${ }^{18}$. De modo que esta información deberá ser custodiada por el órgano designado por cada Universidad para este fin.

\footnotetext{
16 Medida adoptada en los Protocolos de la Universidad de Alicante y Universidad de Valencia.

17 A estos efectos la Universidad de Alicante designa a la Dirección de la Unidad de Igualdad. En otras Administraciones, el Protocolo de actuación frente a las situaciones de acoso sexual, acoso por razón de sexo y acoso laboral en el Tribunal de Cuentas (aprobado por el Pleno el 23 de diciembre de 2013), crea un Órgano para la tramitación de asuntos confidenciales

18 La extensión de esta garantía una vez finalizado el procedimiento se contempla expresamente en el artículo 14.a) del Protocolo de la Universidad de Alicante
} 
La publicación o utilización indebida de esta documentación o información será constitutiva de infracción muy grave conforme al EBEP, en aquellos supuestos en los que el sujeto infractor sea empleado público.

En el caso de los alumnos que sean llamados a intervenir en un procedimiento como testigos, resulta muy importante la firma de una cláusula de confidencialidad por la que se obliguen a su cumplimiento, puesto que el vigente Reglamento de Disciplina Académica de 1954 no tipifica ninguna infracción con este perfil.

Respeto, protección de la dignidad e integridad de las personas afectadas y prohibición de represalias, la protección suele alcanzar a todas las personas participantes en el procedimiento $^{19}$ y se prevé la adopción de medidas disciplinarias contra quien las haya llevado a cabo en gran parte de los protocolos.

Diligencia y celeridad, resultan garantías reiteradas y, como las anteriores también son recogidas en el Protocolo de actuación frente al acoso sexual y al acoso por razón de sexo en el ámbito de la Administración General del Estado y de los Organismos Públicos vinculados a ella.

Imparcialidad y contradicción, la mayor parte de protocolos cuando se refieren a la resolución mediante procedimiento formal garantizan el derecho de audiencia imparcial de cada una de las partes, necesaria para que el órgano competente pueda resolver.

\section{II.GUESTIONES TÉGNICO JURÍDICAS QUE PLANTEAN LOS PROTOCOLOS DE PREVENGIÓN Y ACTUACIÓN GONTRA EL ACOSO SEXUAL Y EL ACOSO POR RAZÓN DE SEXO}

\section{Definición de acoso sexual y acoso por razón de sexo}

La definición de acoso sexual y acoso por razón de sexo que contemplan los Protocolos es la recogida en los artículos 7.1 y 7.2 de la LOI, de este modo, sin perjuicio de lo establecido en el Código Penal, se entiende por:

"Acoso sexual, cualquier comportamiento, verbal o físico, de naturaleza sexual que tenga el propósito o produzca el efecto de atentar contra la dignidad de una persona, en particular cuando se cree un entorno intimidatorio, degradante u ofensivo.

19 En este sentido el artículo 2.1.c) del Protocolo de la Universitat Politècnica de València, aclara que "esta garantía se establece igualmente respecto a terceras personas que formalmente faciliten información o testifiquen en alguna fase del procedimiento" 
Constituye acoso por razón de sexo cualquier comportamiento realizado en función del sexo de una persona, con el propósito o el efecto de atentar contra su dignidad y de crear un entorno intimidatorio, degradante u ofensivo"

Algún Protocolo como el de la Universidad de Alicante, incluye en su ámbito objetivo el acoso por razón de orientación sexual (o identidad de género) que define en base a los artículos 14 y 9.2 de la Constitución y el artículo 21 de la Carta de Niza, como "cualquier comportamiento realizado en función de la orientación sexual de la persona (o la identidad de género) con el propósito o el efecto de atentar contra su dignidad y de crear un entorno intimidatorio, degradante u ofensivo".

En otros, se incluyen situaciones que pueden considerarse ejemplos de acoso ${ }^{20}$ o se añaden conductas calificadas como inapropiadas de tipo sexual o basadas en el sexo de las personas ${ }^{21}$.

En cualquier caso, el órgano con competencia para incoar el procedimiento, tendrá que realizar una valoración previa de la denuncia para decidir si inicia el procedimiento previsto por apreciar una situación que podría ser calificada como acoso, y en caso de ser así, el competente para tramitarlo, deberá emitir un informe de conclusiones que elevará al Rector y en el que deberá proponer alguna de las siguientes alternativas:

a) Archivo del expediente por falta de objeto o insuficiencia de indicios

b) Poner los hechos en conocimiento del Ministerio Fiscal, si la conducta pudiese ser constitutiva de delito

c) La incoación de un expediente disciplinario cuando se considere que concurren indicios suficientes de acoso sexual, por razón de sexo, o en su caso, por orientación sexual.

Desde esta perspectiva, resulta especialmente relevante la doctrina y la jurisprudencia relativas al acoso sexual, tanto en la vertiente penal como en el ámbito sancionador administrativo, puesto que los Protocolos se configuran como un primer

20 El Protocolo de la Facultad d'Economia i Empresa de la Universitat de Barcelona, se refiere a situaciones concretas como hacer insinuaciones sexuales o comentarios denigrantes u obscenos de carácter sexista o por razón de orientación sexual; hacer presión para concretar citas o encuentros sexuales en el entorno universitario o fuera de él; escribir cartas, notas, mensajes electrónicos u otro tipo de mensaje texto de contenido sexual o de carácter ofensivo, etc..

También la Universidad de la Laguna que en su Anexo II recoge "definiciones y clasificaciones orientativas de conceptos relacionados con el acoso sexual y el acoso sexista".

21 En el Protocol per a la detecció, prevenció i actuació en els supòsits d'assetjamente laboral, assetjament sexual i assetjament per raó de sexe a la Universitat Jaume I de Castelló, art.4.6 
filtro para derivar el problema denunciado a cualquiera de las alternativas enunciadas anteriormente

En este sentido, el Tribunal Constitucional manifiesta que "para que exista un acoso sexual ambiental constitucionalmente recusable ha de exteriorizarse, en primer lugar, una conducta de tal talante por medio de un comportamiento físico o verbal manifestado, en actos, gestos o palabras, comportamiento que además se perciba como indeseado e indeseable por su víctima o destinataria, y que, finalmente, se grave, capaz de crear un clima radicalmente odioso e ingrato, gravedad que se erige en elemento importante del concepto. En efecto, la prohibición del acoso no pretende en absoluto un medio laboral a séptico y totalmente ajeno a tal dimensión de la persona, sino exclusivamente eliminar aquellas conductas que generen, objetivamente, y no sólo para la acosada, un ambiente en el trabajo hosco e incómodo. En tal sentido, la práctica judicial de otros países pone de manifiesto que ese carácter hostil no puede depender tan sólo de la sensibilidad de la víctima de la agresión libidinosa, aun cuando sea muy de tener en cuenta, sino que debe ser ponderado objetivamente, atendiendo al conjunto de las circunstancias concurrentes en cada caso, como la intensidad de la conducta, su reiteración, si se han producido contactos corporales humillantes o sólo un amago o quedó en licencias o excesos verbales y si el comportamiento ha afectado al cumplimiento de la prestación laboral, siendo por otra parte relevantes los efectos sobre el equilibrio psicológico de la víctima para determinar si encontró opresivo el ambiente en el trabajo. Así, fuera de tal concepto quedarían aquellas conductas que sean fruto de una relación libremente asumida, vale decir previamente deseadas y, en cualquier caso, consentidas o, al menos, toleradas" $" 22$

El TC sigue el criterio establecido por la Comisión Europea en su Recomendación de 27 de noviembre de 1991, relativa a la protección de la dignidad de la mujer y del hombre en el trabajo, que exige la concurrencia de dos elementos para que una conducta pueda calificarse como acoso sexual: en primer lugar, debe tratarse de un comportamiento físico o verbal grave capaz de crear un clima radicalmente odioso e ingrato y un segundo componente de rechazo por parte de la víctima que ponga de manifiesto su carácter de indeseado ${ }^{23}$.

En cuanto a las conductas subsumibles en el tipo de infracción administrativa de acoso sexual no hay demasiada jurisprudencia. La Sala de lo Contencioso-Administrativo del Tribunal Superior de Justicia de Madrid, se ha pronunciado en varias ocasiones en el mismo sentido "el acoso sexual viene definido como un comportamiento que suponga perseguir, apremiar o importunar a alguien con molestias o requerimientos de indole sexual en el seno de una relación de superioridad laboral, docente o análoga, entre las que cabe incluir las relaciones de prestación de servicios habituales o continuadas...Interesa destacar, en estadio de la argumentación, que el acoso sexual, al constituir un atentado a la libre decisión de no verse involu-

22 STC 224/1999, de 13 de diciembre; STC 136/2001, de 18 de junio

23 $\mathrm{Al}$ respecto MOYA AMADOR (2015): p.682 
crado en una relación, requerimiento o molestia de indole sexual indeseada, está afectando a la esfera intima de la persona, cuya protección proclama el artículo 18.1 de la Constitución, siendo igualmente un reflejo de su dignidad, enfatizado en el artículo 10 de la propia Norma Fundamental... Así, el comportamiento continuado del Sr.X suponía para quienes lo sufrian una actitud molesta o agresiva para su dignidad e intimidad, lo que resulta suficiente para calificar su actitud, de acoso sexual, y ello aunque no haya habido una agresión física hacia alguna de las personas referidas o no se produjera entre personas en situación de jerarquía, porque se trató en todo caso de proposiciones o gestos rechazables, indeseables y molestos, para quienes tenían que soportarlos" ${ }^{24}$

Podría deducirse de este planteamiento que el acoso sexual queda circunscrito a supuestos que se produzcan en el seno de una relación laboral o una relación jurídica de dicha naturaleza. El citado Tribunal rechaza este planteamiento y aclara que "ya en la tipificación del acoso sexual en el Derecho Penal Español, la Ley Orgánica 10/1995, de 23 de noviembre, del Código Penal, dispuso, en su artículo 184, una formulación de dicho comportamiento delictivo en la que no sólo se aludía al prevalimiento de una situación de superioridad laboral, sino que se incluían también en su seno situaciones de prevalimientos en otras relaciones distintas de superioridad como eran la "docente", añadiéndose, incluso, que tal superioridad podía darse en situaciones "análogas". Resulta, además, que se abunda en esta formulación en la reforma que del precepto reseñado se acometió por la Ley Orgánica 15/2003, de 25 de noviembre, en la que se alude, en el tipo básico, a una relación "laboral, docente o de prestación de servicios, continuada o habitual". ${ }^{25}$

Por otra parte, la tipificación del acoso sexual en el Código Penal plantea la cuestión de cuándo la conducta desborda el ámbito administrativo para adentrarse en el ámbito penal. Las manifestaciones más graves se tipifican en el artículo 184 del Código Penal que dispone:

"1. El que solicitare favores de naturaleza sexual, para sí o para un tercero, en el ámbito de una relación laboral, docente o de prestación de servicios, continuada o habitual, y con tal comportamiento provocare a la víctima una situación objetiva y gravemente intimidatoria, hostil o humillante, será castigado, como autor de acoso sexual, con la pena de prisión de tres a cinco meses o multa de seis a 10 meses.

2. Si el culpable de acoso sexual hubiera cometido el hecho prevaliéndose de una situación de superioridad laboral, docente o jerárquica, o con el anuncio expreso o tácito de causar a la víctima un mal relacionado con las legítimas expectativas que

24 STSJ de Madrid, (Sala de lo Contencioso-Administrativo, Sección $7^{\mathrm{a}}$ ) Sentencia núm.10430/2010 de 16 de diciembre. En este mismo sentido STSJ 1623/2009 del TSJ de Madrid de 24 de julio de 2009

25 Fundamento de Derecho Segundo, STSJ de Madrid, núm.10430/2010 
aquélla pueda tener en el ámbito de la indicada relación, la pena será de prisión de cinco a siete meses o multa de 10 a 14 meses.

3. Cuando la víctima sea especialmente vulnerable, por razón de su edad, enfermedad o situación, la pena será de prisión de cinco a siete meses o multa de 10 a 14 meses en los supuestos previstos en el apartado 1, y de prisión de seis meses a un año en los supuestos previstos en el apartado 2 de este artículo.”

Al respecto el Tribunal Supremo ha puntualizado los requisitos típicos de este delito, exigiendo:

“a) Una relación entre denunciante y acusado que debe tener una naturaleza de trabajo profesional de prestación de servicios que constituyó el contexto o ámbito del comportamiento imputado. Ni siquiera se requiere que el sujeto activo del delito ostente condición alguna de superioridad respecto a la víctima. Lo que el tipo penal protege es el derecho a desempeñar la actividad en un entorno sin riesgo para su intimidad y libertad.

b) El comportamiento típico consiste en una directa e inequívoca solicitud a la víctima de comportamientos cuya administración le corresponde en su autonomía sexual. Es de subrayar que esa solicitud no tiene que ser necesariamente verbalizada, bastando que se exteriorice de manera que así pueda ser entendida por la persona destinataria. $Y$ basta, para que la actitud requirente sea típica, que se produzca no obstante el rechazo del destinatario o destinataria. De tal suerte que el delito se consuma desde su formulación, de cualquiera manera que sea, si le sigue el efecto indicado, pero sin que sea necesario que alcance sus objetivos. Es más, de alcanzarlos, podría dar lugar a responsabilidades de otro tipo penal.

c) La víctima debe pasar a una situación que debe objetivamente considerarse no solamente de indudable hostilidad, sino humillante y generadora de temor. No requiere el tipo penal que la víctima sucumba y padezca más trastornos que la mera ubicación en una situación que merezca aquellas calificaciones.

d) Se requiere que el temor y la humillación, asi como la hostilidad, tuvieron objetivamente como causa el comportamiento del acusado." ${ }^{26}$

En cuanto al tipo agravado, del artículo 184.2 del Código Penal, también se ha pronunciado la jurisprudencia requiriendo la presencia de tres elementos:

"a) que se soliciten favores de naturaleza sexual. Este requisito queda cumplido cuando media petición de trato o acción de contenido sexual que se presente seria e inequívoca, cualesquiera que sea el medio de expresión utilizado, cuando dicha conducta resulta indeseada, irrazonable y ofensiva para quien la sufre;

26 ATS, Sala de lo Penal 4908/2015, en este mismo sentido STS 1335/2011 de 26 de abril 
b) que el sujeto se prevalezca de una situación de superioridad laboral, docente o análoga;

c) que anuncie al sujeto pasivo, de modo expreso o tácito, que de no acceder puede causarle un mal relacionado con las legitimas expectativas que pueda tener en el ámbito de dicha relación.

A estos elementos habrá que añadir, al no ser posible la conducta imprudente, que el dolo del sujeto abarque todos los componentes que se dejan reseñados y especialmente el aprovechamiento consciente de su situación de superioridad'27

En estos parámetros, conviene tener en cuenta como señalan MORALES PRATS Y GARCÍA ALBERO ${ }^{28}$ que el ámbito de sujetos activos del tipo básico no aparece recortado, no sólo desde la perspectiva del sexo, sino tampoco desde la posición que ocupen en la relación laboral, docente o de prestación de servicios. Puntualizan que puede existir una relación vertical entre acosador y acosado pero no un peligro en las condiciones laborales, docentes o de la prestación del servicio, en cuyo caso aunque la situación de la víctima pueda considerarse objetiva y gravemente humillante procederá la aplicación del tipo básico y no del tipo cualificado. También advierten que son posibles los acosos por personas en situación de inferioridad, por ejemplo de alumno a un profesor en contextos como el aula, en estos casos en función de la obstinación y reiteración de las solicitudes puede producirse una situación gravemente humillante $\mathrm{u}$ hostil para el profesor.

Por lo que se refiere a la acción típica, se limita a exigir la solicitud de favores sexuales a través de cualquier vía o canal, por lo tanto como señala la doctrina ${ }^{29}$, dicha solicitud podrá ser verbal, escrita o incluso gestual y debe causar en la víctima una situación que pueda ser calificada objetivamente de hostil, humillante o intimidatoria. De este modo, el ilícito penal excluye por una parte solicitudes o insinuaciones que puedan quedar justificadas en un entorno de confianza o amistad en el terreno laboral, así como aquellos supuestos en los que no quepa inferir una solicitud de favor sexual como "chistes, indirectas, sarcasmos, miradas lascivas, incluso pequeños contactos físicos innecesarios (dar palmadas, tocar en partes no íntimas o con significación sexual), despliegue de fotos pornográficas, etc." ${ }^{30}$.

Esto no significa que este tipo de conductas queden impunes. Entendemos que éste precisamente, será el ámbito del derecho administrativo sancionador que rebasará al ámbito penal si el comportamiento reúne los requisitos de acción típica previstos y que exigen la solicitud de favor sexual en el entorno laboral, docente o de

\footnotetext{
27 STS 5157/2000 de 23 de junio

28 MORALES PRATS y GARCÍA ALBERO (2009): pp.323 y sg.

29 Idem, pág.324

$30 \quad$ Idem, pág.325
} 
prestación de servicios y la creación de una situación objetiva y gravemente intimidatoria, hostil o humillante.

Respecto a este último requisito descansará básicamente la determinación de lo punible en este ámbito ${ }^{31}$ y evidentemente dependerá de las circunstancias de cada caso. Como señala ORTS BERENGUER ${ }^{32}$ una situación objetiva y gravemente intimidatoria, hostil y humillante exige que sea real a los ojos de un observador medio y de relevancia suficiente para incidir en la toma de decisiones del sujeto pasivo y colocarlo en un entorno en el que difícilmente puede desenvolverse con libertad y tranquilidad. En este sentido, MORALES PRATS y GARCÍA ALBERO ${ }^{33}$ distinguen entre acoso "horizontal" en el que será necesario el rechazo inequívoco de la víctima y una actitud persistente y abrumadora por el solicitante una vez conocida la negativa del receptor, de un acoso "vertical" en la que no se precisa esa persistencia puesto que la relación de poder constituye un factor preponderante, capaz de generar dicho estado con una sola solicitud.

En cuanto a los tipos cualificados el artículo 184.2, exige abuso de situación de superioridad laboral, docente o jerárquica, o el anuncio expreso o tácito de causar a la víctima un mal relacionado con las legítimas expectativas que aquella pueda tener en el ámbito de la indicada relación. Mientras que el artículo 184.3 se refiere a supuestos en los que la víctima sea especialmente vulnerable, por razón de su edad, enfermedad o situación.

Bajo estas coordenadas y en el contexto de una relación laboral, docente o de prestación de servicios, que es el que nos ocupa, lo que permitirá deslindar el delito de la infracción administrativa, será la existencia de una solicitud de favor sexual que además genere una situación objetiva y gravemente intimidatoria, hostil o humillante, lo que dependerá según los casos, de la persistencia y modos de la solicitud, del grado de prevalencia del solicitante y de la influencia del clima creado en el receptor.

En cuanto al acoso por razón de sexo, se trata de una conducta definida en los protocolos, tipificada como infracción administrativa en el artículo 95.2.b) del TRE$\mathrm{BEP}^{34}$, siempre unida al acoso sexual. Su definición como cualquier comportamiento realizado en función del sexo de una persona, con el propósito o el efecto de atentar contra su dignidad y de crear un entorno intimidatorio, degradante u ofensivo, se conecta en la mayoría de casos con supuestos de trato desfavorable relacionados con el embarazo, la maternidad y la paternidad que tendrán una dimensión laboral regida

\footnotetext{
$31 \quad$ Idem, pág.326

32 ORTS BERENGUER (2015): p.233

33 MORALES PRATS y GARCÍA ALBERO (2009): p.326

34 Real Decreto Legislativo 5/2015, de 30 de octubre, por el que se aprueba el Texto Refundido de la Ley del Estatuto Básico del Empleado Público
} 
según los casos por el Derecho Administrativo o por el Derecho del Trabajo y que en caso de no ser solventado por los procedimientos establecidos en los Protocolos derivará en un proceso judicial.

\section{2. Ámbito subjetivo de los protocolos}

En el ámbito subjetivo de aplicación de los protocolos universitarios, se presenta una cierta diversidad, según el acoso sexual se aborde desde la perspectiva de los riesgos laborales o como un problema de discriminación que requiere una mayor concreción de medidas de actuación. Algunas Universidades como la UNED, la Universidad de Murcia o la Universidad de Valladolid, no incluyen en su ámbito de aplicación a los estudiantes, en cuanto que contemplan sus protocolos como una medida preventiva y reparadora de salud laboral, entendiendo el acoso como un riesgo laboral de carácter psicosocial. Otras Universidades, inscriben los protocolos en sus políticas de género, concretamente como acción para la prevención, detección y resolución de situaciones de acoso, separando los que se refieren a prevención y actuación frente al acoso sexual de los procedimientos de prevención de riesgos laborales y argumentando que el acoso sexual y el acoso por razón de sexo puede producirse entre pares o entre colectivos diferentes ${ }^{35}$.

De esta forma, las Universidades que incardinan sus protocolos de acoso como una medida de salud laboral, no siempre amparan a los mismos sujetos. En el caso de la Universidad de Valladolid y la UNED contemplan como personas protegidas al personal docente e investigador (PDI) y al de administración y servicios (PAS) que preste sus servicios en la Universidad, colectivo de becarios, personal en formación y personal contratado en proyectos de investigación vinculados a la Universidad, cuando desarrollen su actividad dentro del ámbito organizativo de la misma y personal de empresas contratadas, siempre que presten sus servicios en la misma y resulte implicado personal propio de la Universidad ${ }^{36}$. Sin embargo, el protocolo de la Universidad de Murcia solo incluye en su ámbito de aplicación a empleados públicos y becarios que desarrollen su actividad en ella.

Por su parte, otras universidades han contemplado un ámbito subjetivo más amplio y además de los colectivos anteriores, incluyen a personas que bajo la dependencia jurídica de un tercero presten sus servicios en ellas, autónomos y estudiantes.

35 Protocolo de prevención y actuación frente al acoso sexual, por razón de sexo y por orientación sexual de la Universidad de Alicante, Preámbulo, apartado II y III. Siguiendo este mismo criterio Universidad Politécnica de Valencia, Universitat de Lleida, Universidad de La Laguna, Universidad de Cádiz, Universidad Carlos III de Madrid, Universidad de Jaén, Univesitat Jaume I, Universidad del País Vasco, entre otras.

36 Protocolo de actuación en materia de acoso de la UNED y Protocolo de actuación en materia de prevención e inhibición del acoso en el ámbito laboral de la Universidad de Valladolid. 
En este último caso, los protocolos se constituyen en una herramienta realmente eficaz no solo en el ámbito laboral sino también en el entorno académico, cultural, deportivo y/o de servicios de cada Universidad, amparando situaciones muy diversas, acoso entre pares, entre profesor/alumno, entre alumno/profesor, alumno/PAS, PAS/alumno, becario/alumno, alumno/becario, etc..

Quizás el supuesto que queda más lejos de la intervención de la Universidad sería el de acoso en el que ambas partes son personal de empresas que presten sus servicios en el ámbito de la misma. Para estos casos, los protocolos más recientes, han previsto que se sigan los cauces ordinarios y que el informe de conclusiones sea trasladado por el Rector a la empresa para que se adopten las medidas oportunas en el ámbito de cada organización ${ }^{37}$. También, en el supuesto en el que una de las partes sea alumno, PDI o PAS y la otra personal externo, en este caso se tendrán que activar los mecanismos oportunos de coordinación empresarial para la aplicación del respectivo procedimiento y las medidas correctoras oportunas en el ámbito de cada una de ellas ${ }^{38}$.

De este modo, teniendo en cuenta las diversas posibilidades subjetivas contempladas en los protocolos, podemos hablar de diferentes tipologías de acoso en cuanto a los sujetos:

a) Acoso sexual o por razón de sexo entre estudiantes y por estudiantes a otro colectivo, desde esta perspectiva como señala RIVAS VALLEJO ${ }^{39}$, el marco legal que habilitaría a la Universidad para la adopción de medidas de tutela frente al acoso de este colectivo podría ser el artículo 25.1 de la Ley 3/2007 (LOI) que dispone que "las Administraciones educativas garantizarán un igual derecho a la educación de mujeres y hombres a través de la integración activa, en los objetivos y en las actuaciones educativas, del principio de igualdad de trato, evitando que, por comportamientos sexistas o por los estereotipos sociales asociados, se produzcan desigualdades entre mujeres y hombres". Una interpretación amplia de este artículo permite incluir en el ámbito subjetivo de los Protocolos al personal docente, al personal de administración y servicios y a los alumnos, siendo la inclusión del alumnado el elemento fundamental que diferencia este tipo de protocolos de los que contienen los procedimientos de prevención de riesgos laborales ante determinadas situaciones de riesgo psicosocial.

Al margen de este tipo de actuación, el acoso entre estudiantes universitarios no cuenta con una referencia normativa propia, el todavía vigente Reglamento de

37 Protocolos de actuación frente al acoso sexual de la Universidad de Alicante y Universidad Politécnica de Valencia

38 Protocolo de actuación frente al acoso sexual y al acoso por razón de sexo de la Universidad Politécnica de Valencia

$39 \quad$ RIVAS VALLEJO (2015): p.464 
disciplina académica de $1954^{40}$ en su artículo 5.3 tipifica como infracción muy grave "la ofensa grave, de palabra u obra, a compañero, funcionarios y personal dependiente del Centro" en las que podrían tener encaje este tipo de conductas. Si bien lo deseable será que se apruebe el Proyecto de Normativa de convivencia y disciplina académica $^{41}$ de la enseñanza universitaria que tipifica explícitamente los diferentes tipos de acoso como infracción muy grave.

b) Acoso por docentes a otros colectivos y entre docentes, en este acoso se integraría también aquel en el que la víctima es un o una estudiante y acosador un docente, supuesto acuñado como "docenting" "42 que goza de mayor difusión y escándalo en los medios ${ }^{43}$. Estos casos encajarían en el terreno del trabajo y gozan de tipificación específica en el Derecho Administrativo, en el Derecho del Trabajo y en su caso en el Derecho Penal ${ }^{44}$.

c) Acoso por personal de administración y servicios a otros colectivos o entre ellos, que como en el supuesto anterior gozan de tipificación específica en el ámbito del Derecho Administrativo, en el Derecho del Trabajo y en su caso en el Derecho Penal.

d) Acoso entre personal de empresas que prestan sus servicios en la Universidad y cuyo terreno será el del Derecho del Trabajo.

\section{Modalidades de procedimientos de actuación previstos en los Protocolos.}

Algunos protocolos contemplan la mediación como único procedimiento para la resolución de conflictos y prevención del acoso, por ejemplo la Universidad de Murcia la configura como mecanismo para evitar el "enraizamiento de situaciones que, de persistir, podrían perturbar la prestación del servicio público o afectar a los derechos de las personas". Desde esta perspectiva el protocolo garantiza el derecho a invocar le mediación, así como, en su caso, a denunciar las eventuales situaciones de acoso ilícitas y, en consecuencia, este procedimiento se utilizará únicamente para situaciones denominadas de "conflicto interpersonal" y que no implican la existencia de ilícito penal o disciplinario.

\footnotetext{
BOE núm.285 de 12/10/1954

https://web.ua.es/es/coseg/documentos/borrador-anteproyecto-lcda.pdf

RIVAS VALLEJO (2015): p.468

http://www.elespanol.com/espana/sociedad/20170129/189731482 0.html http://politica.elpais.com/politica/2017/01/22/actualidad/1485087608_275751.html

44 STSJ de Galicia (Sala de lo Contencioso-Administrativo) núm.1324/2012; Sentencia núm.29/2012 del Juzgado de lo Social de Vitoria; Sentencia del Juzgado de lo Social de Castellón de la Plana núm.2/2016
} 
No obstante, ésta no suele ser la fórmula habitual y en su mayoría los protocolos diferencian dos situaciones:

a) Resolución mediante procedimiento informal. Se trata de supuestos en los que la resolución mediante diálogo es viable. Se prevé, para aquellos casos, en los que no hay una situación que pueda calificarse como acoso sexual ${ }^{45}$ pero que podría acabar siéndolo si no se actúa, para ello se designará un mediador. Este tipo de solución no busca un diagnóstico con unas consecuencias jurídicas, sino una mediación, de modo que el protocolo se convierte en un instrumento para la resolución del conflicto ${ }^{46}$.

La utilización de esta vía queda sujeta al consentimiento previo de ambas partes, pudiendo actuar como mediador tanto personal propio de la Universidad, como externo con formación específica en materia de mediación y suele exigir el seguimiento de los acuerdos alcanzados para comprobar su efectivo cumplimiento.

b) Resolución mediante procedimiento formal; con carácter alternativo o consecutivo al anterior, es decir, cuando no haya sido posible solucionar el conflicto mediante diálogo, o se hubiera decidido inicialmente seguir este cauce. En estos casos, sí se busca determinar si existe acoso y en su caso, adoptar las consecuencias jurídicas correspondientes.

En este tipo de procedimiento, será un órgano colegiado o unipersonal, normalmente de carácter técnico, el que realice las actuaciones necesarias para la determinación y esclarecimiento de los hechos y proponga al Rector las posibles alternativas: archivo del expediente que ha provocado la denuncia por falta de objeto o insuficiencia de indicios; denuncia ante los órganos jurisdiccionales, si la conducta pudiera ser constitutiva de delito o la incoación de un expediente disciplinario cuando los hechos pudieran encajar en conducta tipificada como infracción administrativa. Por lo tanto, el objeto de este procedimiento es decidir si existe acoso y, en su caso, proponer al órgano ejecutivo correspondiente, normalmente el Rector, la adopción de las medidas procedentes, incoación de expediente disciplinario, adopción de medidas cautelares, etc.. ${ }^{47}$.

Respecto a estos procedimientos GAMERO CASADO ${ }^{48}$ destaca su adecuación en orden a gestionar los expedientes de acoso que se susciten, debido a la dificultad asociada a la tramitación de expedientes disciplinarios y al escrutinio público que puede generar su incoación. Este tipo de inconvenientes, se pueden solventar con

45 Sobre la escala de acoso sexual e interacción social de contenido sexual en el ámbito universitario, vid FERRER-PÉREZ y BOSCH-FIOL (2014): pp.480 y sg.

46 GAMERO CASADO (2011): p.113

47 Ibídem, pág. 114

48 Ibídem 
estos instrumentos, que bajo un criterio de prudencia, prevén una gestión ordenada de los asuntos que se plantean, pudiendo derivarse, si existen motivos fundados para ello, el correspondiente expediente disciplinario.

Por último, señalar respecto a la resolución de estos procedimientos formales, que los protocolos prevén, que una vez tramitados, el órgano unipersonal o colegiado según los casos, emitirá un informe de conclusiones que elevará al órgano ejecutivo correspondiente, en la mayoría de casos el Rector, que dictará resolución. Sin embargo, no contemplan los recursos posibles frente a la misma. Aunque la aplicación de los recursos previstos en los artículos 121 y siguientes de la Ley 39/2015 pueda resultar obvia, hubiese resultado conveniente dada la heterogeneidad de sujetos destinatarios, que se recogiese una breve mención a los mismos en estas normas, diferenciando según el órgano que resuelva entre alzada y reposición.

\section{Aproximación de los procedimientos de resolución formal a la información reservada de un expediente disciplinario}

Como ya se ha indicado, la mayoría de protocolos prevén la resolución mediante diálogo y por procedimiento formal, como mecanismos de resolución, sucesivos. La resolución mediante diálogo, en algunas normas, se contempla como primera instancia, y en caso de frustrarse desembocaría en la resolución mediante procedimiento formal ${ }^{49}$. En otras, se contempla como solución para situaciones que no pueden calificarse como acoso sexual pero podrían acabar siéndolo, siguiéndose el procedimiento formal, únicamente en aquellos casos en los que pueda haber una situación de acoso, con el fin de constatar la existencia de indicios de falta disciplinaria o delito e iniciar, en su caso, el correspondiente expediente disciplinario. Desde esta perspectiva, cabe plantearse si estos procedimientos formales, que tienen por finalidad determinar si hay indicios de que una conducta sea constitutiva de infracción administrativa, pueden asimilarse a la información reservada prevista en el artículo 28 del Reglamento de Régimen Disciplinario de los Funcionarios de la Administración del Estado (RDFP), "El órgano competente para iniciar el procedimiento podrá acordar previamente la realización de una información reservada".

En algunos protocolos, como el de la Universidad de la Laguna ${ }^{50}$, se equipara expresamente la información reservada con el peritaje especializado que, en su caso, ordenará el Rector una vez conocida la denuncia y que resolverá, según los casos, el archivo del expediente o la incoación de expediente disciplinario. Sin embargo, en el resto de Protocolos no se menciona esta cuestión.

\footnotetext{
49 Protocolos como el de la UNED o la Universidad del País Vasco

50 Protocolo para la Detección, Prevención y Actuación en los supuestos de acoso sexual y acoso sexista, artículo 9.4, artículo 15
} 
De la lectura del art.28 RDFP y de las precisiones jurisprudenciales a propósito de este trámite, podríamos considerar como características esenciales de la información reservada:

a) Es un trámite potestativo, "se trata de un trámite potestativo que no inicia "per se" el procedimiento, pero que puede servir de fundamento para iniciarlo, pudiendo entonces unirse al expediente disciplinario. Se trata de una actividad interna o un estudio previo a la incoación del expediente disciplinario"(STS de 8 de julio de 1983) ${ }^{51}$

b) Es un estudio previo que puede servir de fundamento para iniciar el expediente disciplinario ${ }^{52}$, configurándose como un procedimiento accesorio y previo al mismo $^{53}$.

c) Su instrucción no implica en todo caso la iniciación de un expediente disciplinario

d) El órgano competente para acordar este trámite es el que tiene la competencia para iniciar el expediente disciplinario.

La mayoría de estos rasgos son compartidos con la configuración de los procedimientos formales previstos en los Protocolos de Acoso, no obstante se pueden apreciar tres elementos divergentes:

a) En la designación del órgano competente para acordar la iniciación del procedimiento formal, que no siempre coincide con el competente para iniciar el expediente disciplinario en la Universidad, que sería el Rector. Así, en unos casos decide la iniciación del procedimiento formal la Vicerrectora o Vicerrector con competencias en la materia ${ }^{54}$, en otros son órganos especializados los que toman esta decisión $^{55}$ y en algunos se inicia directamente mediante escrito de la persona protegida ${ }^{56}$

b) Los derechos y garantías que asisten al presunto infractor. Sobre este aspecto, la jurisprudencia señala que no existe un derecho del presunto infractor a interve-

$51 \quad$ STSJ de Castilla y León 104/2012 de 24 de abril

$52 \quad$ STS 17 de enero de 1997, Rec.99/1994, La Ley 2995/1997

53 Abogacía General del Estado. Dirección del Servicio Jurídico del Estado, Manual sobre Responsabilidad Disciplinaria del Personal al Servicio de las Administraciones Públicas, Aranzadi Thomson Reuters, 2010, pág.265

54 Es el supuesto previsto por la Universidad de Alicante, la Universitat Politècnica de València o la Univesitat de Valècia o la Universidad Carlos III de Madrid, entre otras.

${ }_{55}$ En el caso de la Universidad de Valladolid es el Equipo Técnico de Evaluación del Acoso o la Unidad de Igualdad entre Mujeres y Hombres en el caso de la Universidad de Cádiz.

56 Protocolo de la UNED, que contempla esta posibilidad en los supuestos en que el proceso de resolución acordada mediante diálogo no hubiesen concluido satisfactoriamente, artículo V.1. 
nir en la información reservada ${ }^{57}$ y sin embargo la participación de las partes objeto de conflicto y la contradicción es una garantía contemplada en todos los protocolos.

c) Algunos protocolos prevén como alternativas a la recepción del escrito de solicitud de intervención, entre otras, el inicio del procedimiento o la propuesta de incoación de expediente de información reservada ${ }^{58}$, lo que manifiesta una intención clara de diferenciar la información reservada de este tipo de procedimientos.

En base a ello, podemos concluir que aunque la finalidad de estos procedimientos sea la de determinar la existencia de indicios para iniciar un expediente disciplinario, no reúne los requisitos necesarios para poder ser considerada como una información reservada, de modo que las reglas aplicables a uno y a otro no van a ser las mismas.

Cuestión diferente sería el procedimiento de actuación previsto en el Protocolo de la Universidad de la Laguna que lo califica como información reservada y reconoce explícitamente el derecho de las partes a participar a través de declaraciones, informes periciales y cualquier otra documentación que deseen aportar. En este caso, se configura expresamente el procedimiento como una información reservada y por lo tanto se expele la posibilidad de una información reservada posterior.

La cuestión no es baladí, en cuanto que la consideración de este tipo de actuaciones como información reservada desembocaría en aquellos supuestos en que se apreciasen indicios de ilícito en un expediente disciplinario pero en caso de no tener esta naturaleza podría dar lugar a un expediente de información reservada previo a un hipotético procedimiento disciplinario.

Con estas coordenadas, podemos concluir que aunque de la tramitación del procedimiento previsto en los diferentes protocolos pueda derivarse la iniciación de un expediente disciplinario cuando se observe una conducta que pudiera ser calificada como acoso sexual, cuenta con unas reglas y unas garantías diferentes a las de la información reservada, no siendo por lo tanto equiparables. En consecuencia y en función de si se cuenta con indicios fehacientes, el informe de conclusiones de los procedimientos formales podrá recomendar al Rector la incoación de un expediente disciplinario cuando existan pruebas, información o hechos que permitan fundar la posible existencia de infracción de acoso sexual y/o acoso por razón de sexo, pero en el supuesto de que no se cuente con suficientes fundamentos se podrá recomendar la incoación de un expediente de información reservada previo a la iniciación de un expediente disciplinario.

${ }^{57} \quad$ STS 17 de mayo de 1999, Rec.5262/1993, La Ley 8884/1999 y STSJ de Castilla y León, Valladolid, de 28 de septiembre de 2001 (JUR 2001, 328230)

58 Protocolo de la Universitata Politècnica de València, art.4.1.1.c y d 


\section{La adopción de medidas provisionales}

Suele ser habitual en los protocolos la previsión de adopción de medidas provisionales por el órgano competente para resolver, una vez recibida la denuncia y en cualquier fase del procedimiento previsto. Este es el caso de la Universidad de La Laguna, Universitat Jaume I, Facultat d'Economia i Empresa de la Univesitat de Barcelona, Universidad de Alicante, Universidad de Sevilla o Universitat de Lleida.

Aunque la denominación de estas medidas, en algunos casos es de cautelares y en otros de provisionales ${ }^{59}$, su tratamiento por las Universidades es muy similar; se pueden adoptar en cualquier fase, son propuestas al órgano competente para resolver por el órgano técnico que tramita las denuncias, deben ser motivadas y tienen como finalidad garantizar la protección de las personas afectadas por conductas constitutivas de acoso y asegurar el buen funcionamiento del servicio.

La aplicación de estas medidas se realizará conforme a su regulación específica prevista en el artículo 56 de la Ley 39/2015, que prevé como objetivo de las mismas, asegurar la eficacia de la resolución que pudiera recaer. No obstante, en estos casos la finalidad perseguida no es tanto ésta, sino como se ha indicado, garantizar la protección de las personas afectadas y el buen funcionamiento del servicio. En este sentido, refiriéndose a la adopción de estas medidas en el procedimiento disciplinario, REBOLLO PUIG ${ }^{60}$ afirma que la suspensión provisional de funcionarios no persigue la eficacia de la resolución sino el buen funcionamiento del servicio que en muchos casos podría estar en peligro si el expedientado continuase desempeñando sus funciones, optando en consecuencia por una interpretación amplia de la "eficacia de la resolución" que incluya el logro efectivo de los intereses públicos. A este respecto, también el Tribunal Supremo configura las medidas provisionales como acciones que se adoptan para proteger el interés general, tanto en el seno de un procedimiento como con carácter previo a su instrucción ${ }^{61}$.

Una cuestión clave, es el momento oportuno para la adopción de estas medidas. Al respecto, los protocolos prevén que pueda ser en cualquier fase desde la presentación de la reclamación o denuncia, previsión con cobertura específica en el apartado segundo del citado artículo 56 que permite que puedan adoptarse con carácter

59 Como señala la doctrina estas medidas pueden adjetivarse tanto cautelares como provisionales puesto que se anticipan a una medida definitiva final y tienen como finalidad asegurar la eficacia en sentido amplio de la resolución final. Vid. GONZÁLEZ-PÉREZ y GONZÁLEZ NAVARRO (2003): p.1829

60 REBOLLO PUIG (1993 a): pp.662-665

61 STS de 14 de noviembre de 2007, Fundamento de Derecho Quinto "Constituyen, por tanto, acciones provisionales que se adoptan para proteger el interés general, ordinariamente en el seno de un procedimiento, pero también con carácter previo a su instrucción cuando hay razones de urgencia. Se trata de evitar que mientras se instruye y termina un procedimiento puedan mantenerse situaciones que mermen o eliminen la eficacia real de la decisión o resolución que finalmente fuere adoptada" 
previo "en los casos de urgencia inaplazable y para la protección provisional de los intereses implicados". En estos casos, el acuerdo de iniciación que necesariamente deberá producirse dentro de los quince días siguientes a su adopción deberá confirmar, modificar o levantar dichas medidas. En el supuesto de que no se iniciase el procedimiento en este plazo o el acuerdo de iniciación no contuviese un pronunciamiento expreso acerca de las mismas, dichas medidas quedarían sin efecto (artículo 56 Ley 39/2015).

En cuanto a las clases de medidas, algunos protocolos incluyen específicas como limitar el contacto entre la víctima y el presunto agresor, la suspensión temporal del trabajo o de la actividad académica ${ }^{62}$; cambio de unidad, servicio, departamento o grupo de la víctima ${ }^{63}$; movilidad de las personas implicadas de Centro, grupo o turno de trabajo teniendo preferencia de elección la presunta víctima ${ }^{64}$ y también otras complementarias a las anteriores como la atención médica, psicológica y/o social ${ }^{65}$.

Necesariamente, estas medidas han de conciliarse con la relación prevista en el artículo 56.3 de la Ley 39/2015 que incluye de forma expresa las medidas provisionales que podrán acordarse, en los términos previstos en la Ley 1/2000 de Enjuiciamiento Civil: "suspensión temporal de actividades, prestación de fianzas; retirada o intervención de bienes productivos o suspensión temporal de servicios por razones de sanidad, higiene o seguridad, el cierre temporal del establecimiento por estas u otras causas previstas en la normativa reguladora aplicable; embargo preventivo de bienes, rentas y cosas fungibles computables en metálico por aplicación de precios ciertos; el depósito, retención o inmovilización de cosa mueble; la intervención y depósito de ingresos obtenidos mediante una actividad que se considere ilícita y cuya prohibición o cesación se pretenda; consignación o constitución de depósito de las cantidades que se reclamen; la retención de ingresos a cuenta que deban abonar las Administraciones Públicas; aquellas otras medidas que, para la protección de los derechos de los interesados, prevean expresamente las leyes, o que se estimen necesarias para asegurar la efectividad de la resolución”.

Hasta la Ley 39/2015, el legislador había seguido un sistema de numerus apertus en el que no tipificaba las medidas provisionales teniendo en cuenta la diversidad de procedimientos y de posibles resoluciones a las que estas medidas pueden servir ${ }^{66}$. Sin embargo el citado artículo 56.3 parece cambiar la tendencia cuando dispone "..podrán acordarse las siguientes medidas provisionales..”, resulta evidente el cambio y

\footnotetext{
62 Protocolo de la Universitat de Lleida Protocolo de la Universitat Jaume I Protocolo de la Universidad de Sevilla Protocolo de la Universidad de La Laguna GONZÁLEZ-PÉREZ y GONZÁLEZ NAVARRO (2003: p.1874)
} 
la intención del legislador de mostrar una serie preferente de medidas provisionales con carácter no cerrado, en cuanto que en su último apartado establece "aquellas otras medidas que, para la protección de los derechos de los interesados, prevean expresamente las leyes, o que se estimen necesarias para asegurar la efectividad de la resolución”. Puede interpretarse que la intención del legislador con la inclusión de este último apartado, es abrir la posibilidad de adoptar medidas provisionales no mencionadas en los apartados anteriores y que sean más ajustadas a los principios de proporcionalidad, eficacia y menor onerosidad, en cuanto que no parece lógico que para los casos que ocupan el objeto de este estudio por ejemplo, se adopte en cualquier caso la suspensión temporal de actividad si la persona denunciada es empleado público aunque ello resulte desproporcionado.

Así las cosas, queda justificado que desde la presentación de la denuncia y hasta la finalización del procedimiento, el órgano competente teniendo en cuenta la gravedad de los hechos, pueda adoptar las medidas cautelares que estime procedentes para proteger a las personas afectadas y asegurar el buen funcionamiento del servicio bajo el paraguas de los principios de proporcionalidad, efectividad y menor onerosidad.

Respecto al tipo de medidas, nos inclinamos por una interpretación amplia del artículo 56.3 que incluiría no solo la suspensión temporal de actividades sino cualquier otra que resulte adecuada, siempre que conforme al artículo 56.4, no causen un perjuicio de difícil o imposible reparación a los interesados o impliquen violación de derechos amparados por las leyes.

Otra cuestión que se plantea, es si es necesaria la audiencia del interesado para su adopción. La regulación del artículo 56 de la Ley 39/2015 no contempla esta exigencia y tampoco los Protocolos, no obstante algunas decisiones jurisprudenciales han contemplado esta garantía ${ }^{67}$ y parte de la doctrina se muestra favorable a este trámite cuando puedan suponer una limitación de los derechos e intereses legítimos de los interesados ${ }^{68}$, o en aquellos casos en que no se cuente con "elementos de juicio suficientes" ${ }^{\prime \prime}$.

En esta línea argumental, TARDÍO $\mathrm{PATO}^{70}$ defiende la aplicación analógica de los artículos 131 y 135 de la LJCA que prevén la audiencia para la adopción de la medida cautelar, salvo en supuestos de especial urgencia en los que se convocará a las

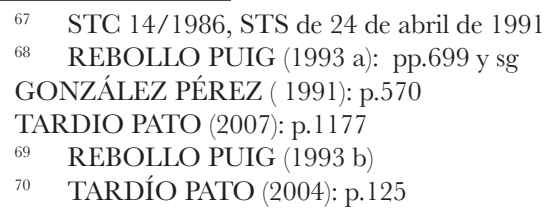


partes a una comparecencia, dentro de los tres días siguientes a su adopción, para decidir sobre el alzamiento, mantenimiento o modificación de la medida adoptada.

Bajo estos parámetros y en el marco de los procedimientos previstos en los protocolos, entendemos que la audiencia del interesado no resulta necesaria en todo caso puesto que no viene exigida por la LPA, pero si será oportuna para que el órgano administrativo tenga "elementos de juicio suficientes" para adoptar la medida cautelar, de modo que si pudiese existir algún tipo de duda sobre la suficiencia de los elementos de juicio disponibles, será necesario escuchar previamente al interesado para que pueda alegar lo que estime conveniente. La línea argumental sostenida y conforme a lo previsto en un gran número de Protocolos, mantiene que este tipo de medidas pueden adoptarse en cualquier momento desde la recepción de la denuncia y resulta muy difícil que en ese momento se disponga de elementos suficientes para su adopción; entendemos en consecuencia, que cuando más temprana sea esta decisión mayor necesidad existirá de utilizar este trámite.

En cuanto a la impugnabilidad de estas medidas, el artículo 56.2 final del primer párrafo prevé expresamente la posibilidad de interponer el recurso que proceda en el caso de medidas provisionales previas a la iniciación del procedimiento administrativo. Para el resto de casos, tanto la doctrina como la jurisprudencia considera el acuerdo de su adopción como un acto de trámite cualificado y por tanto susceptible de recurso de forma autónoma ${ }^{71}$.

\section{Sobre la inversión de la carga de la prueba}

El artículo 13 de la LO 3/2007 para la Igualdad Efectiva de Mujeres y Hombres, dispone:

"1. De acuerdo con las Leyes procesales, en aquellos procedimientos en los que las alegaciones de la parte actora se fundamenten en actuaciones discriminatorias, por razón de sexo, corresponderá a la persona demandada probar la ausencia de discriminación en las medidas adoptadas y su proporcionalidad ${ }^{72}$.

$71 \quad$ STS de 8 de febrero de 1980 (RJ 1980, 362), STS de 28 de enero de 1985 (RJ 1985, 150), STS de 9 de mayo de 1991 (RJ 1991, 6613), STS de 11 de mayo de 1999 (RJ 1999,4918), citadas por ABOGACÍA DEL ESTADO (2010)

72 De este modo, la Ley de Igualdad integraba en nuestro ordenamiento las exigencias del derecho comunitario previstas en la Directiva 97/80/CE del Consejo, de 15 de diciembre de 1997, relativa a la carga de la prueba en los casos de discriminación por razón de sexo, la Directiva 2000/43/CE, del Consejo, de 29 de junio, relativa a la aplicación del principio de igualdad de trato de las personas independientemente de su origen racial o étnico y la Directiva 2000/78/CE del Consejo, de 27 de noviembre, relativa al establecimiento de un marco general para la igualdad de trato en el empleo y la ocupación. 
A los efectos de lo dispuesto en el párrafo anterior, el órgano judicial, a instancia de parte, podrá recabar, si lo estimase útil y pertinente, informe o dictamen de los organismos públicos competentes.

2. Lo establecido en el apartado anterior no será de aplicación a los procesos penales"

Asimismo, las Disposiciones Adicionales $5^{\circ}$ y $6^{\circ}$ de la Ley incorporan esta previsión en el artículo 217 de la Ley de Enjuiciamiento Civil y en el artículo 60 de la Ley de Jurisdicción Contencioso-Administrativa.

Esta disposición ha sido incorporada en la mayoría de Protocolos universitarios de actuación frente al Acoso Sexual, disponiendo que en los procedimientos que regulan, corresponderá a la persona demandada probar la ausencia de discriminación en las medidas adoptadas y su proporcionalidad ${ }^{73}$.

Esta previsión plantea dos cuestiones, la primera es si el legislador está planteando un desplazamiento total de la carga de la prueba hacia el presunto infractor y la segunda si cuando se excluye esta inversión de la carga de la prueba en procesos penales se están excluyendo también los procedimientos administrativos sancionadores y los contenciosos administrativos derivados de éstos, en cuanto que también constituyen una manifestación del ius puniendi del Estado.

En cuanto a la primera, implica valorar si aquí el legislador quiere seguir la trayectoria marcada por la legislación laboral que requiere "indicios fundados ${ }^{74}$ " de discriminación para que se desplace la carga de la prueba al demandado o si quiere iniciar una nueva tendencia en los procesos civiles y contenciosos exigiendo simplemente que "las alegaciones de la parte actora se fundamenten en actuaciones discriminatorias" para que se produzca tal desplazamiento. Como señala Ituren i Oliver $^{75}$, la cuestión no es baladí, pues supondría interpretar que la LEC y la LJCA en estas cuestiones contemplan una verdadera inversión de la carga de la prueba hacia el demandado, lo que en muchas ocasiones se convertiría en una auténtica prueba diabólica para el mismo.

73 Protocolo para la detección, prevención y actuación en los supuestos de acoso sexual y de acoso sexista de la Universidad de la Laguna, art.10; Protocol d'Actuació enfront de l'assetjament sexual i de l'assetjament per raó de sexe en l'àmbit de la Universitat de València, art.4.2; Protocolo de Prevención y Actuación frente al Acoso Sexual, por Razón de Sexo y por Orientación Sexual de la Universidad de Alicante, art.22.3; Protocol de la Universitat de Barcelona per a la prevenció, la detecció y l'actuació contra les situacions d'assetjament sexual i per raó de sexe o d'orientació sexual, art.VIII.2

74 Artículo 96 LPL

75 ITUREN I OLIVER (2008): p.256 
Respecto a esta cuestión el Tribunal Constitucional es claro, así en la STC 31/2014 ${ }^{76}$ recoge: "..Ahora bien, como también ha declarado repetidamente este Tribunal, para que se produzca este desplazamiento al demandado del onus probando no basta simplemente con que el actor tache la medida de discriminatoria, sino que, además, "ha de acreditar la existencia de indicios que generen una razonable sospecha, apariencia o presunción a favor de su alegato" (SSTC 136/1996, de 23 de julio, FJ6, y 48/2002, de 25 de junio, FJ 5). Sólo, pues, cuando esto último sucede, la parte demandada asume "la carga de probar la existencia de causas suficiente, reales y serias para calificar de razonable su decisión" y destruir así la sospecha o presunción de lesión constitucional generada por los indicios (STC 98/2003,de 2 de junio, FJ2)"

"En este punto, como ya dijimos en la STC 144/2006, de 8 de mayo, Ff4", "para apreciar la concurrencia del indicio tendrán aptitud probatoria, tanto los hechos que sean claramente indicativos de la probabilidad de la lesión del derecho sustantivo, como aquéllos que, pese a no generar una conexión tan patente, y resultar por tanto más fácilmente neutralizables, sean sin embargo de entidad suficiente para abrir razonablemente la hipótesis de la vulneración del derecho fundamental. Esto es, son admisibles diversos resultados de intensidad en la aportación de la prueba que concierne a la parte actora, pero habrá de superarse inexcusablemente el umbral mínimo de aquella conexión necesaria, pues de otro modo, si se funda la demanda en alegaciones meramente retóricas, o falta la acreditación de elementos cardinales para que la conexión misma pueda distinguirse, haciendo inverosímil la inferencia, no se podrá pretender el desplazamiento del onus probandi al demandado"

"En definitiva, el o la demandante que invoca la aplicación de la regla de la prueba indiciaria debe desarrollar una actividad alegatoria suficientemente precisa y concreta en torno a los indicios de la existencia de discriminación. Alcanzando, en su caso, el anterior resultado probatorio, sobre la parte demandada recaerá la carga de probar la existencia de causas suficientes, reales y serias, para calificar de razonable y ajena a todo propósito lesivo del derecho fundamental la decisión o práctica empresarial cuestionada, único medio de destruir la apariencia lesiva creada por tales indicios (STC 2/2009, de 12 de enero, FJ3)"

En consecuencia, el Tribunal Constitucional deja claro que se requieren indicios fundados de discriminación para que se desplace la carga de la prueba al demandado, criterio seguido en procesos civiles, en procesos laborales y en procesos contencioso-administrativos. De este modo, a nuestro juicio, no existe una inversión de la carga de la prueba real, en cuanto que la actuación de la parte demandada se configura como una reacción, que requiere necesariamente, que la parte actora haya podido acreditar con carácter previo "la existencia de indicios que generen una razonable sospecha, apariencia o presunción a favor de su alegato" 77

$76 \quad$ STC $31 / 2014$ de 24 de febrero, FJ $3^{\circ}$

77 STC 136/1986 de 26 de julio 
Teniendo en cuenta lo anterior, nos sumamos a la tesis sostenida por LOUSADA AROCHENA ${ }^{78}$ de que no estamos ante una auténtica inversión de la carga de la prueba en sentido estricto, sino de una modulación de la regla general o de una flexibilización de la actividad probatoria, que en todo caso, exige una actividad alegatoria suficientemente precisa y concreta de la parte actora en torno a los indicios de la existencia de discriminación ${ }^{79}$.

Sentada la premisa de que no estamos ante una inversión de la carga de la prueba en sentido estricto, sino de una flexibilización de la actividad probatoria que exige la aportación de indicios. La segunda cuestión que cabe plantear, es si la exclusión prevista en el apartado segundo de este artículo 13 respecto a los procesos penales se extiende también a los procedimientos administrativos sancionadores y los contenciosos administrativos derivados de éstos. En este sentido se han pronunciado algunas disposiciones legislativas, tanto anteriores como posteriores a la LOI, relacionadas con la igualdad de trato y no discriminación.

Así, la el artículo 20 de la Ley 51/2003 de igualdad de oportunidades, no discriminación y accesibilidad universal de personas con discapacidad, tras contemplar esta inversión de la carga de la prueba prevé en su apartado segundo "lo establecido en el apartado anterior no es de aplicación a los procesos penales ni a los contencioso administrativos interpuestos contra resoluciones sancionadoras".

En esta misma línea la Ley 11/2014 de la Generalitat de Cataluña para garantizar los derechos de lesbianas, gays, bisexuales, transgéneros e intersexuales y para erradicar la homofobia, la bifobia y la transfobia, en el artículo 30.1 dispone la inversión de la carga de la prueba y en el apartado 4 "lo establecido en el apartado 1 no es aplicable a los procesos penales ni a los procedimientos administrativos sancionadores".

No ocurre lo mismo en la Ley $62 / 2003^{80}$ que al regular las medidas en materia de igualdad de trato y no discriminación por el origen racial o étnico de las personas, dispone en su artículo 32 "En aquellos procesos de origen jurisdiccional civil y del orden jurisdiccional contencioso-administrativo en los que las alegaciones de la parte

78 LOUSADA AROCHENA (2003): p.45 explica como en la búsqueda de aliviar las dificultades probatorias de las conductas discriminatorias, la Sentencia 38/81, de 23 de noviembre, del Tribunal Constitucional, inicia una doctrina que es bautizada como de inversión de la carga de la prueba y que fue ratificada en numerosas sentencias posteriores. No obstante, no se trata de una inversión de la carga de la prueba por simple alegación de discriminación sino que requiere la aportación de algún elemento fáctico.

79 Este planteamiento se plasma expresamente en el Protocolo de la Unviersitat de Barcelona que contempla la previsión del artículo 13 de la Ley Orgánica 3/2007 y añade "A la part reclamant li correspon, prèviament, aportar els indicis necessaris d'assetjament desencadenants de la inversión de la càrrega probatòria"( art.VIII.2)

80 Ley 62/2003 de medidas fiscales, administrativas y de orden social 
actora se deduzca la existencia de indicios fundados de discriminación por razón del origen racial o étnico de las personas, corresponde al demandado la aportación de una justificación objetiva y razonable, suficientemente probada, de las medidas adoptadas y de su proporcionalidad”. En iguales términos se pronuncia el artículo 36 en materia de igualdad de trato y no discriminación en el trabajo, no excluyendo, en consecuencia, los procedimientos administrativos sancionadores.

Tampoco la doctrina se muestra unánime en esta cuestión, así para autores como AGUADO I CUDOLÁ ${ }^{81}$, refiriéndose a las previsiones de los artículos 32 y 36 de la citada Ley 62/2003, señala que se trata de una medida "especialmente relevante tanto en los casos en los que la administración realice estas discriminaciones; por ejemplo, el despido de un empleado público por su orientación sexual o por su origen racial, como también en los casos en que estas vulneraciones sean producidas entre particulares y la administración realice una función arbitral o sancionadora", no excluyendo la aplicación de esta medida en procedimientos sancionadores.

En sentido totalmente opuesto, otros autores extienden la exclusión prevista para los procedimientos penales a los procedimientos administrativos sancionadores y a los contenciosos derivados de éstos, en cuanto que también constituyen una manifestación del ius puniendi del Estado ${ }^{82}$ y por tanto la presunción de inocencia debe repeler cualquier otro planteamiento de reparto de la carga de la prueba.

No nos planteamos si en los procedimientos administrativos sancionadores y en los contenciosos derivados de los mismos es aplicable la presunción de inocencia, no cabe duda. Así el Tribunal Constitucional, Sala Segunda núm.138/90, de 17 de septiembre, establece que "La presunción de inocencia especialmente concebida, en principio, como garantía del proceso penal, es aplicable, más allá del mismo, a todo acto del poder público, sea administrativo o judicial, mediante el cual se castiga una conducta de las personas definida en la Ley como infractora del ordenamiento jurídico y, por tanto, también despliega sus efectos protectores en el orden administrativo disciplinario, constituyendo una presunción iuris tantum que garantiza el derecho a no sufrir pena o sanción que no tenga fundamento en una previa actividad probatoria sobre la cual el órgano competente pueda fundamentar un juicio razonable de culpabilidad.."83

Abundando en esta misma cuestión la STS 4429/2012, FJ.2 recoge "..pues bien, como también señala la sentencia 40/2008, de 3 de marzo del Tribunal Constitucional, la presunción de inocencia rige sin excepciones en el ordenamiento sancionador y ha de ser respetada en la imposición de cualesquiera sanciones, sean penales, sean administrativas, pues el ejercicio del ius

\footnotetext{
81 AGUADO I CUDOLÁ (2013)

82 En este sentido se pronuncian ITUREN I OLIVER (2008) y PÉREZ GIL (2008)

83 En esta misma línea SSTC 197/1995, 71/1998, 40/2008, 32/2009 y SSTS de 21 de mayo de
} 1987, 25 de febrero de 1998, 21 de diciembre de 1998, 17 de octubre de 2001, 6 de junio de 2012 
puniendi en sus diversas manifestaciones está condicionado por el art.24.2 al juego de la prueba y a un procedimiento contradictorio en el que puedan defenderse las propias posiciones, significando a continuación que "el derecho a la presunción de inocencia comporta que la sanción esté basada en actos o medios probatorios de cargo o incriminadores de la conducta reprochada; que la carga de la prueba corresponde a quien acusa, sin que nadie esté obligado a probar su propia inocencia, y que cualquier insuficiencia en el resultado de las pruebas practicadas, libremente valorado por el órgano sancionador, debe traducirse en un pronunciamiento absolutorio.."

Queda fuera de toda duda esta cuestión, el principio de presunción de inocencia rige en cualquier manifestación de ius puniendi del Estado. No obstante cabe plantearse si la flexibilización de la actividad probatoria de la que hablamos y que se recoge en el artículo 13 de la LOI puede hacer quebrar esta presunción.

Desde esta perspectiva, entendemos que se trata de una medida que trata de facilitar la prueba, exigiendo a la víctima un principio de prueba revelador de la existencia de un panorama indiciario ${ }^{84}$, desencadena en el demandado la carga de probar la existencia de las causas que las puedan justificar, sin que ello en sí suponga una transgresión al principio de presunción de inocencia o indefensión por el acusado. Siguiendo esta argumentación, sostenemos que no se trata de un olvido del legislador ${ }^{85}$ sino que deliberadamente se está incluyendo esa flexibilización de la carga de la prueba en los procedimientos sancionadores y los procesos judiciales por infracción administrativa, siguiendo la orientación comunitaria contenida en la Directiva 97/80/CE ${ }^{86}$ relativa a la carga de la prueba en los casos de discriminación por razón de sexo, que extiende su ámbito de aplicación a cualquier procedimiento civil o administrativo relativo a los sectores público o privado, con excepción de los procedimientos extrajudiciales ${ }^{87}$.

En definitiva y siguiendo nuestro planteamiento inicial resulta ajustada a Derecho la previsión relativa a la inversión de la carga de la prueba en los procedimientos frente al acoso sexual previstos en los Protocolos; así como en los procedimientos disciplinarios que pudieran derivarse de los mismos. Entendiendo que no es una inversión de la prueba en sentido estricto, sino una flexibilización de la misma, que exigirá a la víctima la aportación de indicios para que desencadene en la parte denunciada la carga de probar la existencia de las causas que puedan justificar su actuación.

${ }^{84}$ STC $144 / 2006$, FJ.6 ${ }^{\circ}$

85 Así lo sostiene ITUREN I OLIVER (2008)

${ }^{86}$ Directiva 97/80/CE del Consejo de 15 de diciembre de 1997, relativa a la carga de la prueba en los casos de discriminación basada en el sexo. DO, L 014 de 20/01/1998, pág.6-8

87 Conforme al Considerando 12 se está refiriendo a procedimientos de mediación y conciliación 


\section{III.GONGLUSIONES}

En los últimos años, las Universidades Públicas han elaborado protocolos de prevención e intervención frente a situaciones de acoso sexual y por razón de sexo, que establecen pautas de actuación específicas para hacer frente a este tipo de situaciones. No obstante, estos instrumentos presentan cierta diversidad de base, según el acoso se aborde desde la perspectiva de los riesgos laborales de carácter psicosocial o como un problema de género, en el que se comprenden ámbitos que exceden del estrictamente laboral.

Cualquiera que sea la perspectiva desde la que se aborda esta cuestión, las Universidades han querido dotar a estos instrumentos de carácter normativo, aprobándose por el correspondiente órgano de gobierno de cada una de ellas. De este modo, quedan vinculados a los mismos, todos los colectivos incluidos en su ámbito de aplicación (funcionarios, personal laboral, alumnos según los casos) en el marco de su relación especial de sujeción con la Universidad.

El polimorfismo del acoso sexual, permite su tratamiento desde diversas perspectivas jurídicas, lo que posibilita diferentes conceptualizaciones según el enfoque. En el caso de los protocolos, la definición de acoso es la contemplada en la Ley Orgánica de Igualdad, incluyendo cualquier conducta de naturaleza sexual que tenga un propósito o produzca un efecto degradante, ofensivo u intimidatorio. Por su parte, el tipo penal exige el contexto de una relación laboral, docente o de prestación de servicios y la solicitud de favor sexual que genere objetivamente una situación gravemente intimidatoria, hostil o humillante. Bajo estas coordenadas, la delimitación del ámbito penal y administrativo no siempre resulta fácil, dependerá según los casos, de la existencia o no de solicitud de favor sexual, de la contumacia y formas de la misma, del grado de prevalencia del solicitante y de la influencia del clima creado en el receptor.

Los protocolos articulan procedimientos de diagnóstico, éstos constituyen un filtro previo a la incoación de expedientes disciplinarios, permitiendo gestionar las situaciones de acoso conforme a un patrón y unas garantías preestablecidas, que precisamente son las que hacen diferenciar los mismos de la información reservada, prevista en el artículo 28 del Real Decreto 33/1986 de Régimen Disciplinario de los Funcionarios de la Administración General del Estado. De este modo, será factible la incoación de un expediente de información reservada derivado de la tramitación de un procedimiento formal cuando el órgano competente para resolver no cuente con indicios fehacientes para tomar una decisión.

Una de las dificultades que presenta la tramitación de los procedimientos previstos en los protocolos, es garantizar la confidencialidad respecto a la identidad de todas y cada una de las personas que intervienen y de la información derivada del 
mismo. Las medidas dispuestas son limitadas e insuficientes. Para su plena operatividad, se propone la concreción en cada fase del procedimiento de las medidas necesarias, como la asignación de códigos numéricos identificativos de las partes, custodia de toda la documentación por una único órgano, consulta de actas in situ o la firma de cláusulas de confidencialidad para cada uno de los sujetos que intervenga en el procedimiento.

Otra cuestión esencial, es la recepción en este tipo de procedimientos de la inversión de la carga de la prueba prevista en el artículo 13 de la LOI ya que plantea ciertas dudas en cuanto a su compatibilidad con el principio de presunción de inocencia. Al respecto, la doctrina y la legislación no es unánime y no se cuenta con jurisprudencia contencioso-administrativa que delimite esta cuestión. Sin embargo, la jurisdicción social y las orientaciones comunitarias relativas a la carga de la prueba en los casos de discriminación por razón de sexo, permiten sostener la viabilidad de esta medida, su compatibilidad con el principio de presunción de inocencia y su extensión a los procedimientos sancionadores y procesos judiciales por infracción administrativa de discriminación por razón de sexo.

En definitiva, los protocolos frente al acoso en cualquiera de sus manifestaciones, constituyen un instrumento eficaz de las Universidades para garantizar la dignidad de todas las personas que desarrollen cualquier tipo de actividad en su ámbito territorial. No obstante su aplicación, y especialmente, en lo relativo a la tramitación de los procedimientos formales o de diagnóstico, pueden plantear ciertas dificultades técnico-jurídicas que exigirán la progresiva adaptación e interpretación de sus disposiciones en la práctica de los órganos competentes para su aplicación. 


\section{BIBLIOGRAFÍA}

ABOGAGÍA DEL ESTADO, DIREGGIÓN DEL SERVICIO JURÍDICO DEL ESTADO (2010): Manual sobre Responsabilidad Disciplinaria del Personal al Servicio de las Administraciones Públicas, ed.Thomson Reuters

AGUADO I GUDOLÁ, Vicenç (2013): "La prueba en el proceso contencioso-administrativo: ¿supletoriedad de la legislación procesal civil o necesidad de una regulación específica?" en http://biblio.juridicas.unam.mx

BODELÓN GONZÁLEZ, Encarna y GALA DURÁN, Carolina (2014): "Teoría y Práctica de los Protocolos frente al acoso sexual", en Nueva Revista Española de Derecho del Trabajo, núm.162, pág.101

FERRER- PÉREZ, Victoria y BOSCH-FIOL, Esperanza (2014): “ La percepción del acoso sexual en el ámbito universitario”, en Revista de Psicología social, vol.29, núm.3, pp. 480 y sg.

GAMERO CASADO, Eduardo (2011): "El acoso laboral en la Universidad: Consecuencias Jurídicas y Gestión de Conflictos”, en Temas laborales, núm.110, pp.113 y sg.

GONZÁLEZ PÉREZ, Jesús (1991): Comentarios a la Ley de Procedimiento Administrativo, Civitas, pág. 570

GONZÁLEZ PÉREZ, Jesús y GONZÁLEZ NAVARRO, Francisco (2003): Comentarios a la Ley de Régimen Furídico de las Administraciones Públicas y del Procedimiento Administrativo Común, Madrid, Thomson-Civitas, p.1829

GINES I FABRELLAS, Anna (2009): "La prevención del acoso sexual y por razón de sexo en la Administración Pública”, en El Estatuto Básico del Empleado Público, Madrid, Ministerio de Trabajo e Inmigración, pp.218-219.

ITUREN I OLIVER, Albert (2008): Sala Franco T. (Coord.), Comentarios a la Ley Orgánica 3/2007, de 22 de marzo, para la Igualdad Efectiva de Mujeres y Hombres, La Ley, p.256

LOUSADA AROCHENA, José Fernando (2003): “La sanción administrativa del acoso sexual”, en Revista técnico laboral, vol.25, núm.95, pp.45 y sg.

MORALES PRATS, Fermín y GARGÍA ALBERO, Ramón (2009): "Delitos contra la libertad e indemnidad sexual", en Comentarios a la Parte Especial del Derecho Penal, 8 a ed., Pamplona, Aranzadi, pp. 323 y sg.

MOYA AMADOR, Rosa (2015) "Tutela Laboral", en Tratamiento Integral del Acoso, Pamplona, Aranzadi, p.682 
ORTS BERENGUER, Enrique (2015): "Delitos contra la libertad e indemnidad sexuales (I): agresiones sexuales", Derecho Penal. Parte Especial, $4^{\mathrm{a}}$ ed., Valencia, Tirant lo Blanch, p.233

PÉREZ GIL, Julio, (2008): “La carga de la prueba en la Ley orgánica 3/2007, para la igualdad efectiva de mujeres y hombres" en Igualdad de género: una visión jurídica plural. Fornadas de igualdad efectiva: realidad o ficción, Burgos, 2008

PUMAR BELTRÁN, Nuria (2015): "Los Protocolos de actuación frente al acoso: dónde existen, dónde operan y dónde son eficaces. Ejemplos de derecho comparado", en Tratamiento Integral del Acoso, Pamplona, Aranzadi, p.278

REBOLLO PUIG, Manuel (1993a): "Medidas provisionales en el procedimiento administrativo", en Estudios en Homenaje al Profesor fesús González Pérez, Madrid, Civitas, pp.662-665

REBOLLO PUIG, Manuel (1993b):“Interesados y denunciantes en el Procedimientos Administrativo Sancionador", en Procedimiento Administrativo en Derecho Comparado, Civitas y Consejería de Presidencia de la Junta de Andalucía

RIVAS VALLEJO, Pilar (2015): “Acoso en la Enseñanza Superior”, en Tratamiento Integral del Acoso, Pamplona, Aranzadi, pp.464 y sg.

TARDÍO PATO, José Antonio (2004): "Las medidas provisionales en el procedimiento administrativo", en Revista Furídica de Navarra, núm.38, p.125

TARDÍO PATO, José Antonio (2007): "Medidas provisionales", en El procedimiento administrativo común, Valencia, Tirant lo Blanch, p.1177 